\title{
Effects of provisioning on shark behaviour: Reply to Brunnschweiler \& McKenzie (2010)
}

\author{
Eric Clua ${ }^{1, *}$, Nicolas Buray ${ }^{2,3}$, Pierre Legendre ${ }^{4}$, Johann Mourier $^{2,3}$, Serge Planes $^{2,3}$ \\ ${ }^{1}$ Secretariat of the Pacific Community, BPD5, Noumea, New Caledonia \\ ${ }^{2}$ Ecole Pratique des Hautes Etudes, UMR 5244 CNRS-EPHE-UPVD, \\ Laboratoire "Ecosystèmes Aquatiques Tropicaux et Méditerranéens", Université de Perpignan, 66860 Perpignan, France \\ ${ }^{3}$ Centre de Recherches Insulaires et Observatoire de l'Environnement (CRIOBE - UMS 2978 EPHE CNRS), BP 1013, \\ 98729 Moorea, French Polynesia \\ ${ }^{4}$ Département de sciences biologiques, Université de Montréal, C.P. 6128, succursale Centre-ville, Montréal, \\ Québec H3C 3J7, Canada
}

\begin{abstract}
Brunnschweiler \& McKenzie (2010; Mar Ecol Prog Ser 420:283-284) expressed reservations over the findings of Clua et al. (2010; Mar Ecol Prog Ser 414:257-266), mostly related to the lack of a reference site or a control group in the methodology. In our study, we distinguished between 39 individuals of sicklefin lemon sharks Negaprion acutidens, mainly based on photo-identification. Our study was based on the field-survey approach, with time (a continuous variable) as the source of variation, and thus a control group was not necessary. We provide here additional data that support the notion that abundance of lemon sharks on the provisioning site was increasing, both in their number and fidelity. We maintain our conclusion that sicklefin lemon shark provisioning off Moorea Island can continue, but should be more intensely controlled.
\end{abstract}

KEY WORDS: Field survey approach $\cdot$ Lack of control site $\cdot$ Shark abundance $\cdot$ Site fidelity $\cdot$ Shark conservation

We are grateful to our colleagues J. M. Brunnschweiler and J. McKenzie for their interest in our article about the behavioural response of sicklefin lemon sharks Negaprion acutidens to underwater provisioning in French Polynesia (Clua et al. 2010). To their major issues we respond as follows.

\section{(1) Methodology for assessing shark behaviour}

Applying reliable methods for assessing shark behaviour is a challenge. We assured the quality of our observations by identifying each individual lemon shark through photo-identification, as detailed in a separate paper (Buray et al. 2009). Our study com- prised a relatively low number of sharks (39), while photo-identification allows independent and reliable diagnoses for much larger numbers, e.g. 159 whale sharks Rhincodon typus (Meekan et al. 2006) or 194 nurse sharks Gynglymostoma cirratum (Castro \& Rosa 2005). In that context, the references to Samoilys \& Carlos (2000) and Edgar et al. (2004) made by Brunnschweiler \& McKenzie (2010, p. X) are irrelevant as those authors discuss biases linked to underwater visual censuses (UVC) of several small-sized, highly mobile and hard to distinguish coral reef finfishes. There is no logical or factual link between the potential biases discussed in these studies and the individual identification of large sharks moving in a restricted area, as in our study. When discussing the biases in 
shark observation methodology, Ward-Paige et al. (2010, p.5) even state 'When the goal of a scientific study is to examine relative spatial and temporal differences in the density of a single species surveyed under homogenous sampling conditions, non-instantaneous UVC count data may produce satisfactory information'. This is actually the case for our study.

\section{(2) Arbitrary use of non-defined terms}

'Real provisioning' refers to any anthropogenic provisioning of sharks with a sizeable amount of food that they can acquire, and does not rely only on the olfactory attraction of food, usually described as 'chumming' or 'baiting'.

We anticipated difficulties in understanding of some of our statements, when no previous references are available. Therefore, we defined what we considered to be 'atypical dominance behaviour' (Clua et al. 2010, p. 262) with the following sentence: 'As the study progressed, in addition to a strong residency pattern, this shark showed increasing aggression towards its male and female conspecifics and, to a lesser degree, toward divers (N. Buray pers. obs.).' We think this explanation is clear.

For a better understanding of the imminent risk of long-term feeding, we referred to the observed behaviour of lemon sharks over time, see Section (4). Unfortunately, there are no scientific studies fully describing the natural behaviour of lemon sharks, so we had to rely on statements by our team of experienced scientific divers who have accumulated thousands of hours of underwater observations.

\section{(3) Justifying and quantifying 'increased aggression'}

At its adult stage, Negaprion acutidens cannot be considered to be a gregarious species (Stevens 1984). In contrast to other sharks with a solitary behaviour but a capacity to aggregate and compete, such as white shark Carcharodon carcharias (McCosker 1985) or tiger shark Galeocerdo cuvier (E. Clua pers. obs.), aggressiveness over food does not occur in the wild for lemon sharks (see Nelson \& Johnson 1980). Therefore, we maintain that provisioning sicklefin lemon sharks may create a non-natural source of intra-specific aggressiveness (Clua et al. 2010, p. 263). We are willing to modify this statement only if evidence is presented that $N$. acutidens are prone to natural intraspecific aggressiveness by reason of food in the wild.

The 'lack' of a base line for assessing and quantifying the increasing aggression is a particular aspect of the critique discussed in Section (4) below.

\section{(4) Lack of a control site}

Many experimenters compare their 'treatments' with 'controls' and evaluate their data by analysis of variance (ANOVA). Field survey ecologists may use another approach: the observations are carried out along one or several gradients represented by continuous variables, so that there is no need for an independently-set control to draw conclusions (Hurlbert 1984, Legendre \& Legendre 1998). In our study, we used this field survey approach with 'time' as a continuous variable. We demonstrated an increase in shark aggregation by plotting the number of shark sightings as a function of time and computing linear regressions (see Fig. 4 in Clua et al. 2010). There is a significant increase in the number of sightings of individual sharks in Groups A, C and D across the 44 mo of the study. As natural aggregation of sicklefin lemon sharks does not exist in the wild (see Section 3), it was not possible to carry out a study at a control site.

\section{(5a) Provisioning and intraspecific aggression}

As stated in Section (3), there is no evidence that lemon sharks are aggressive over food in the wild. Therefore, artificial provisioning is most likely adding another cause for intraspecific aggression to the existing competition for mating. Clua et al. (2010) do not directly link the feeding process to an increased competition for mating. However, provisioning, which produces artificial aggregation, during or right after the mating season may raise the level of intra-specific aggression, and may be the cause of obvious wounds on male lemon sharks which are more likely to fight for dominance (N. Buray pers. obs.). Fig 5b in Clua et al. (2010) gives an example of a wounded male; the total number of such wounds, however, was not anecdotal. In the context of our study over $44 \mathrm{mo}$, which did not focus on intraspecific dominance, we presented the accumulated information on the increased aggression amongst males after the mating season as an incidental result. It was a qualitative analysis that compared observations from different seasons, rather than a conclusion based on quantitative data.

\section{(5b) Increase in shark abundance}

In the context of Clua et al. (2010), the term 'abundance' can be understood in different ways: (1) as a purely quantitative term (number of shark sightings, not regarding the number of different individuals); (2) 
as a purely qualitative concept (number of different sharks involved in a given number of sightings); and (3) as a mix of these 2 concepts. We agree that the accuracy of our data does not allow us to use the term 'abundance' in the second or third sense. However, our results (see Fig. 4 in Clua et al. 2010) allow us to use the term for the number of shark sightings. We are pleased to provide here complementary data, not included in our original article, showing that, in addition to an increase in site fidelity, our data also support our hypothesis of a significant increase with time in the number of distinct sharks involved in the sightings (Fig. 1). Both graphs show that the provisioning site was increasingly frequented. From this observation we derived our statement that 'In the case of lemon sharks, their increased site fidelity can have a negative effect on gene flow' (Clua et al. 2010, p. 263).

\section{(5c) Loss of genetic variability}

At the end of our discussion (Clua et al. 2010, p. 264), we cautiously stated that 'Because the studied population is small, daily aggregations at the same location could result in increased social interactions and increased mating between close relatives, reinforcing the risk of inbreeding.' We were not saying that there was any present loss. We think readers will be able to appreciate the difference between a 'risk', which includes a probability for not happening, and a 'fact', which does not allow any room for an alternative, and needs to be supported.

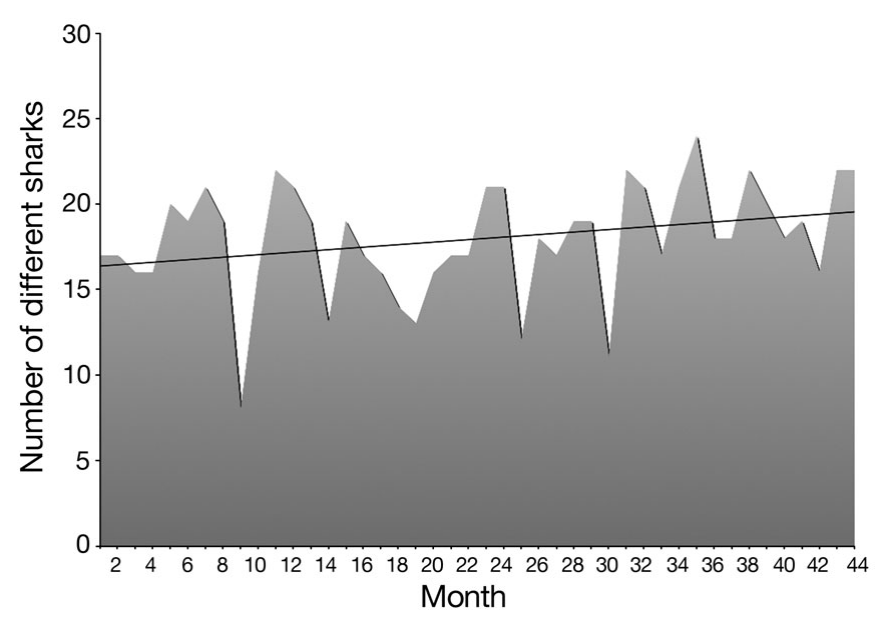

Fig. 1. Negaprion acutidens. Number of different sharks contributing to the sightings during the course of the study (44 mo). The line representing the linear trend supports the hypothesis of a significant increase (at the usual 5\% significance level) in the number of sharks at the feeding site (1-tailed $t$-test of significance of the slope, $\mathrm{p}=0.029$ ).

\section{CONCLUSIONS}

Clua et al. (2010) provided (1) reliable information (2) in a specific case (3) about a controversial subject. The consideration of provisioning as an asset for conservation of endangered species (Bookbinder et al. 1998, Halpenny 2003), however, does not automatically allow the results of Clua et al. (2010) to be generalised to other feeding sites or shark species. We concluded that sicklefin lemon shark provisioning off Moorea Island can continue but should be better controlled. Our recommendations were specifically addressed to the French Polynesian management authorities (Clua et al. 2010, p. 266). At this stage, we are not advocating a ban on shark feeding. We are currently assessing the direct income generated by lemon shark ecotourism and its importance for the local economy of Moorea Island. This information should convince fishermen of the benefits of shark conservation (Clua et al. unpubl.). However, shark-feeding management still requires studies addressing a variety of subjects and situations, hopefully including further contributions by our colleagues J. M. Brunnschweiler and J. McKenzie.

\section{LITERATURE CITED}

Bookbinder MP, Dinerstein E, Rijal A, Cauley H, Rajouria A (1998) Ecotourism's support of biodiversity conservation. Conserv Biol 12:1399-1404

Brunnschweiler JM, McKenzie J (2010) Baiting sharks for marine tourism: Comment on Clua et al. 2010. Mar Ecol Prog Ser 420:283-284

Buray N, Mourier J, Planes S, Clua E (2009) Underwater photo-identification of sicklefin lemon sharks, Negaprion acutidens, at Moorea (French Polynesia). Cybium 33: 21-27

Castro ALF, Rosa RS (2005) Use of natural marks on population estimates of the nurse shark, Ginglymostoma cirratum, at Atol das Rocas Biological Reserve, Brazil. Environ Biol Fishes 72:213-221

Clua E, Buray N, Legendre P, Mourier J, Planes S (2010) Behavioural response of sicklefin lemon sharks Negaprion acutidens to underwater feeding for ecotourism purposes. Mar Ecol Prog Ser 414:257-266

> Edgar GJ, Barrett NS, Morton AJ (2004) Biases associated with the use of underwater visual census techniques to quantify the density and size-structure of fish populations. J Exp Mar Biol Ecol 308:269-290

Halpenny EA (2003) NGOs as conservation agents: achieving conservation through marine ecotourism. In: Garrod B, Wilson JC (eds) Marine ecotourism: issues and experience. Channel View Publications, Clevedon, p 107-121

Hurlbert SH (1984) Pseudoreplication and the design of ecological field experiments. Ecol Monogr 54:187-211

Legendre P, Legendre L (1998) Numerical ecology, 2nd English edn. Elsevier, Amsterdam

McCosker JE (1985) White shark attack behavior: observations of and speculations about predator and prey strategies. Mem Southern Calif Acad Sci 9:123-135

Meekan MG, Bradshaw CJA, Press M, McLean C, Richards 
A, Quasnichka S, Taylor JG (2006) Population size and structure of whale sharks Rhincodon typus at Ningaloo Reef, Western Australia. Mar Ecol Prog Ser 319:275-285

Nelson DR, Johnson RH (1980) Behavior of the reef sharks of Rangiroa, French Polynesia. Natl Geogr Soc Res Rep 12: 479-499

Samoilys MA, Carlos G (2000) Determining methods of underwater visual census for estimating the abundance of

Editorial responsibility: Hans-Heinrich Janssen, Oldendorf/Luhe, Germany coral reef fish. Environ Biol Fishes 57:289-304

Stevens JD (1984) Life-history and ecology of sharks at Aldabra Atoll, Indian Ocean. Proc R Soc Lond B Biol Sci 222:79-106

Ward-Paige C, Mills Flemming J, Lotze HK (2010) Overestimating fish counts by non- instantaneous visual censuses: Consequences for population and community descriptions. PLoS ONE 5:e11722

Submitted: November 5, 2010; Accepted: November 19, 2010 Proofs received from author(s): December 3, 2010 